\title{
Editorial
}

\section{Discover Materials: the pathway to explore materials as activators of the challenges of the future}

\author{
Rodrigo Martins ${ }^{1}$
}

(c) The Author(s) $2020 \quad$ OPEN

Today we are engaged in promoting science for the benefit of the whole world and to create a better standard of living for all. This implies that we need to exploit the activators able to answer to the demands of such relevant challenges as far as creativity and innovation are concerned. In this respect, materials offer a variety of solutions that stem from, or have been enhanced by, the perception we have that "Materials are everywhere-even in our body!". Moreover, we must avoid residues as waste through reuse, recycling and circularity to serve a Green Agenda and bring prosperity for all.

Also, our future developments will be grounded in the new capabilities offered by digital and communication techniques. These open the challenges of artificial intelligence, industry 4.0 technologies, the Internet of Things (loT), or Internet of Everything (loE), and bring new relationships, which will have an important impact on discovering new materials.

\section{Aims and scopes of the journal}

To support this, we created "Discover Materials", as part of the Discover journal series committed to providing a streamlined submission process, rapid review and publication, and a high level of author service at every stage. It is a broad, open access journal publishing research from across all fields where materials are activators for the innovations and disruptions expected, providing cutting-edge research findings to researchers, academicians, students, and engineers. It considers all parts of the value chain, from fundamental and applied research to the synthesis, characterisation, modelling and application of materials.

\section{Future expectations and challenges}

As a new journal that aims to be on the front line of these discoveries, we especially welcome papers connected to socalled 'green materials', which offer unique properties including natural abundance, low toxicity, economically affordability and versatility in terms of physical and chemical properties. They are the activators of an eco-sustainable economy serving all innovation sectors. Indeed, they can be applied in numerous scientific and technological applications including energy, electronics, building, construction and infrastructure, materials science and engineering applications, as well as pollution management and technology. For instance, green materials can be developed as a source for energy harvesting, tackling new outcome fields that will impact strongly on our development such as hydrogen, synthetic green fuels or the future exploitation of integrated nanogenerators to back up smart, recyclable and disposable platforms for a plethora of applications.

Rodrigo Martins, rfpm@fct.unl.pt | ${ }^{1}$ Materials Science Department, Faculty of Science and Technology of New University of Lisbon, Campus de Caparica, 2829-516 Caparica, Portugal.

Discover Materials $\quad$ (2021) 1:1 $\quad$ https://doi.org/10.1007/s43939-020-00002-8 
Green materials, including biomass-based sources, can be developed as a source for biodiesel and bioethanol production. Biomass-based materials also can be transformed into advanced functionalized materials for applications such as the transformation of chitin into chitosan which can be further used for biomedicine, biomaterials and tissue engineering applications.

Recently, cellulose-based and lignocellulose-based materials as a source for developing functional materials attracted the potential prospect for biomaterials, reinforcing materials and nanotechnology. Furthermore, the development of pigment materials has been gaining interest by using green materials as a source due to their unique properties.

Green materials for electronics, are a key vector concerning the integration of novel devices on conformable, flexible substrates with free-of-form surfaces for innovative product development. Here we highlight the exploitation of green electronics for a plethora of emerging applications such as flexible large-area printed electronics and photonics field which includes among others, hybrid thin film transistors (TFTs), printed electronics and circuitry, (bio-)sensors, in-vitro diagnostic platforms, photovoltaics (PV), nanogenerators and energy storage media, mostly, away from silicon that includes inorganic oxides at the nanoscale, biocompatible polymers, paper and hybrid sustainable materials.

We also welcome new developments grounded in Artificial Intelligence to model, design and simulate the materials and the ability to gain new insights into materials by discovering new patterns and relations in the data. This allows us to shape the needs of our future as far as materials functionality and exploitation on products and systems are concerned. For instance, it can support the realization of materials by design, which can provide multiple functionalities, as demanded by the "Internet of Things", where their processing capacity will enable systems to interact with the environment and express diverse functionalities. This includes validation by experimental physics-based simulations; machine learning approaches tailored for materials data and applications; high-throughput density functional theory calculations of materials properties; model explainability and interpretability to accelerate or simplify materials characterization.

\section{What we built and offer to you}

To answer these demands, Discover Materials aims to cover challenging topics connected to Structural Materials; Functional Materials; Energy Materials; Biological and Biomedical Materials; Polymeric Materials; Materials for interfaces and films coating; Materials modelling, design and simulation. For this we count on the support of a prestigious and multidisciplinary editorial board, composed of some of the leading experts in the field of materials as an enabler and activator to serve a broad range of fields.

The colleagues listed on the website below are part of this effort: https://www.springer.com/journal/43939/editors

Moreover, the journal counts on an editorial advisory board with many well-known experts in the field that provides input about the right pathways for the journal concerning the expected science and technology challenges, for which, the best available knowledge on matters is required.

Together, we endeavour to deliver a high-quality service to our authors, and ensure their papers are not only processed according to the highest standards, but they are also speedily handled.

To make all this happen we count on a fully committed editorial team. This first issue will be the trigger to bring together this strong materials community, for a global common purpose where together we realise and acknowledge the progress of materials as the enabler and activator of our progress.

Please, join us and together we will answer these demands by allowing the science community to share the advances we make. Our journal will contribute to a better understanding of materials, exploit their multi functionalities, understand how to design them and apply them in devices, systems and products, crosscutting a plethora of scientific and application areas.

Please, feel free to contact us if you have any ideas or suggestions. We would welcome a dialogue with you.

Open Access This article is licensed under a Creative Commons Attribution 4.0 International License, which permits use, sharing, adaptation, distribution and reproduction in any medium or format, as long as you give appropriate credit to the original author(s) and the source, provide a link to the Creative Commons licence, and indicate if changes were made. The images or other third party material in this article are included in the article's Creative Commons licence, unless indicated otherwise in a credit line to the material. If material is not included in the article's Creative Commons licence and your intended use is not permitted by statutory regulation or exceeds the permitted use, you will need to obtain permission directly from the copyright holder. To view a copy of this licence, visit http://creativecommons.org/licenses/by/4.0/.

Publisher's Note Springer Nature remains neutral with regard to jurisdictional claims in published maps and institutional affiliations. 